\title{
Effectiveness of kinesiotaping and Acu-TENS on maternal and neonatal outcomes in the first stage of labor among primigravidas
}

\author{
Roshini Rajappan $^{1 *}$, Shivaranjani Balamurugan ${ }^{2}$, Karthikeyan Selvaganapathy $^{3}$
}

\begin{abstract}
${ }^{1}$ College of Physiotherapy, Sri Ramakrishna Institute of Paramedical Sciences, Coimbatore, Tamil Nadu, India ${ }^{2}$ Department of physiotherapy, Sri Narayana Medical Centre, Chennai, Tamil Nadu, India

${ }^{3}$ Sree Abirami College of Physiotherapy, Coimbatore, Tamil Nadu, India
\end{abstract}

Received: 21 October 2019

Revised: 04 December 2019

Accepted: 13 December 2019

\author{
*Correspondence: \\ Dr. Roshini Rajappan, \\ E-mail: roshiniraj@gmail.com
}

Copyright: ( ) the author(s), publisher and licensee Medip Academy. This is an open-access article distributed under the terms of the Creative Commons Attribution Non-Commercial License, which permits unrestricted non-commercial use, distribution, and reproduction in any medium, provided the original work is properly cited.

\section{ABSTRACT}

Background: The common reason for rise in elective Caesarean Section (CS) rate among primigravidas is maternal request due to labor pain fear. Many non-pharmacological pain relief strategies are available to help women cope with labor pain, providing a positive and satisfactory birth experience. The objective of this study was to evaluate effects of $\mathrm{KT}$ and Acu-TENS on maternal and neonatal outcomes in primigravidas.

Methods: 40 full-term primigravidas with an age range of 20-40 years were enrolled into the study by convenience sampling method and divided into 2 groups. Group A received KT and Group B received Acu-TENS. Both groups received breathing exercises. Pain assessment at various cervical dilatation levels were carried out for all participants before and after treatment using Visual Analogue Scale (VAS). Duration of active phase in first stage labor, mode of delivery and neonatal well-being were measured following delivery.

Results: Group A experienced VAS score reduction significantly more than Group B, p=0.004; $<0.05$. There was no significant change in active phase duration of first stage labor between Group A and Group B, p=0.319; >0.05. CS rate was increased in Group A [35\% (7/20)] than in Group B [25\% (5/20)], but neonatal outcomes were not different. Conclusions: This study proves that KT produced significantly better pain relief than Acu-TENS in first stage labor among primigravidas. Acu-TENS showed reduction in active phase duration of first stage labor than KT. Both interventions can safely be used non-invasively for labor pain relief.

Keywords: Acu-TENS, Caesarean, Kinesiotaping, Labor pain, Primigravid, Visual analogue scale

\section{INTRODUCTION}

Labor is a physiological process in which conception products are expelled from the uterus after a minimum period of 20 weeks. The labor stages include, stage 1 which is from labor onset until full dilation of cervix; stage 2 from full cervical dilatation to expulsion of fetus and stage 3 where expulsion of placenta occurs. Pain experienced by mothers during first stage of labor are primarily due to cervical dilation, contraction of uterine muscle and pressure of uterus on the surrounding sensitive structures. The contraction pain rises as intrauterine pressure increases and as cervix dilates. Pain pathways during first stage of labor are primarily from T11 and T12, secondarily from T10 and L1 with pain distribution diffused over a larger area in the lower abdomen and back. The best parameters to decide progress of labor are cervix dilatation and fetal head descent. ${ }^{1,2}$

Caesarean Section (CS) rates have increased globally, from $6.7 \%$ in 1990 to $19.1 \%$ in 2014 , which represents a 
12.4\% absolute increase. ${ }^{3}$ National Family Health Survey (NFHS) - 4 revealed that CS rate in India had increased from $20.3 \%$ to $34.1 \%$, while in Tamil Nadu, the rate of CS had increased from $8.5 \%$ to $17.2 \%$ over the last decade. ${ }^{4,5}$ The commonest reason for rise in elective CS rate was maternal request due to fear of painful vaginal delivery especially among primigravidas. ${ }^{6-11}$ Prompt action is needed to lessen high rates of elective CS's by improving women's knowledge about the risks, benefits of different modes of delivery, offering safe and effective resources for pain and anxiety control during labor which in turn lead to a positive maternal attitude towards vaginal delivery. ${ }^{12}$

Numerous pharmacological and non-pharmacological methods of pain relief help a woman to lessen her anxiety and pain during childbirth. Pharmacological methods of pain relief like oral medications, entanox and epidural analgesia were associated with adverse effects on the mother and new born while non-pharmacological methods like relaxation techniques, massage, breathing exercises, music, aromatherapy, partner support, warm baths, acupuncture, acupressure, TENS and kinesiotaping (KT) were used to modify the woman's response to pain and enhance her coping mechanism by concept of a pain "neuromatrix", in which pain perception is modulated by multiple influences and also contribute to better maternal and neonatal outcomes without any adverse effects. ${ }^{13}$

The KT method was developed by Kenzo kase which consists of an elastic adhesive tape applied on the skin. Recent studies have demonstrated the effect of KT on pain relief during first stage of labor. The most appropriate application site of KT is the dermatome of uterine innervations and over the anterior lower abdomen where radiating pain is felt. ${ }^{14,15}$ Acupuncture-like TENS (Acu-TENS) applied over traditional acupuncture points like Li4 (Hegu) and Sp6 (Sanyinjiao) are used to modulate labor pain. ${ }^{16-17}$

Breathing exercises such as diaphragmatic and costal breathing enable a woman for better control of her labor response. Breathing during labor allows women to identify normal breathing pattern, promote relaxation and concentration, serves as a signal to initiate breathing patterns at the beginning and end of a contraction as labor progresses. $^{18,19}$ The objective of this study was to compare the effectiveness of KT and Acu-TENS with breathing exercises on maternal and neonatal outcomes in first stage of labor among primigravidas.

\section{METHODS}

This was a quasi-experimental study conducted in the Department of Obstetrics and Gynaecology at Sri Ramakrishna Hospital in Coimbatore after getting permission from the hospital Dean and OBG specialist doctors. Informed consents were obtained from all patients and were included for the study after referral from the obstetrician through a complete obstetrical examination. A total of 40 primigravid women who fulfilled the selection criteria were assigned to Group A $(n=20)$ and Group B $(n=20)$. Participants in Group A received KT with breathing exercises, while Group B participants received Acu-TENS with breathing exercises.

Primigravidas with gestation period of $>37$ weeks; aged 20 to 40 years; in first stage of labor experiencing regular painful, minimum 2 palpable uterine contractions every 10 minutes, cervical dilatation $3-5 \mathrm{~cm}$; single fetus in uterus with cephalic presentation and normal Fetal Heart Rate (FHR) were included in the study. Patients with preeclampsia, eclampsia, placenta previa, multiple pregnancies, intrauterine growth retardation, premature rupture of membranes, breech presentation, cephalopelvic disproportion, skin abnormalities, sensory disturbances, metal implants in upper or lower limbs and multigravid were excluded from this study.

In Group A, the kinesiotape with specification of $5 \mathrm{~cm} \mathrm{x}$ $5 \mathrm{~cm}$ was used. Before taping, the patient's skin was prepared by thorough cleaning, rendering free of oil and lotions. When cervical dilatation was $>3 \mathrm{~cm}$, the tape was applied over lumbosacral region on bilateral erector spine muscles through " $\mathrm{H}$ " technique by asking participants to flex their back with an overall 15-25\% tension applied on the tape. The tape ends were applied with no tension. The third strip was applied horizontally as a space correction technique with $100 \%$ tension (Figure 1). ${ }^{20}$

During cervical dilatation $>7 \mathrm{~cm}$, the tape was applied over anterior lower abdomen from left lateral side of last 3 ribs towards right lateral side of last 3 ribs. This is "I" technique and overall $25 \%$ tension was applied on the tape, but tape ends were applied with no tension (Figure 2). After labor completion, the tape was removed in direction of hair growth by pressing skin at end of the taped area and gently it was peeled to minimize patient discomfort.

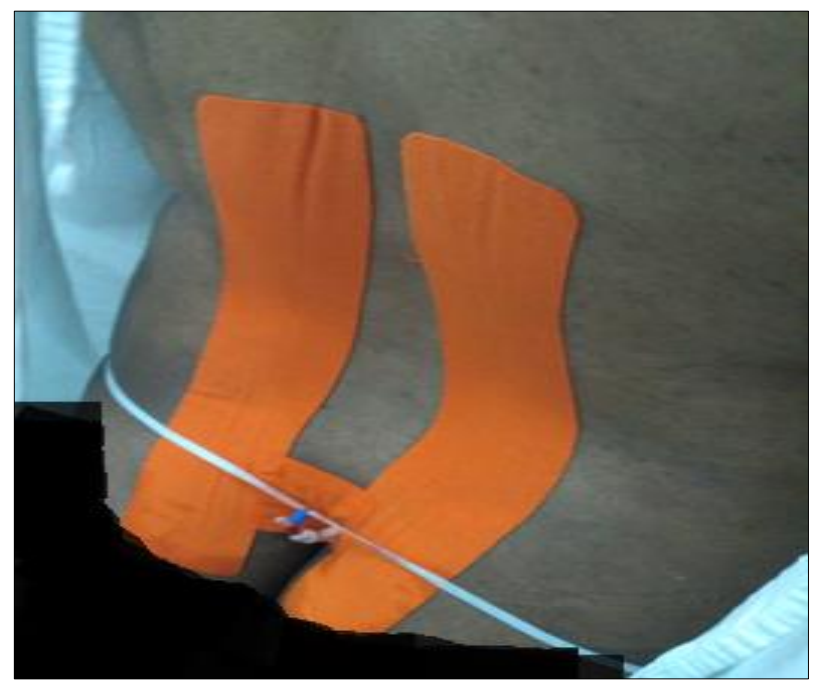

Figure 1: KT 'H' technique. 


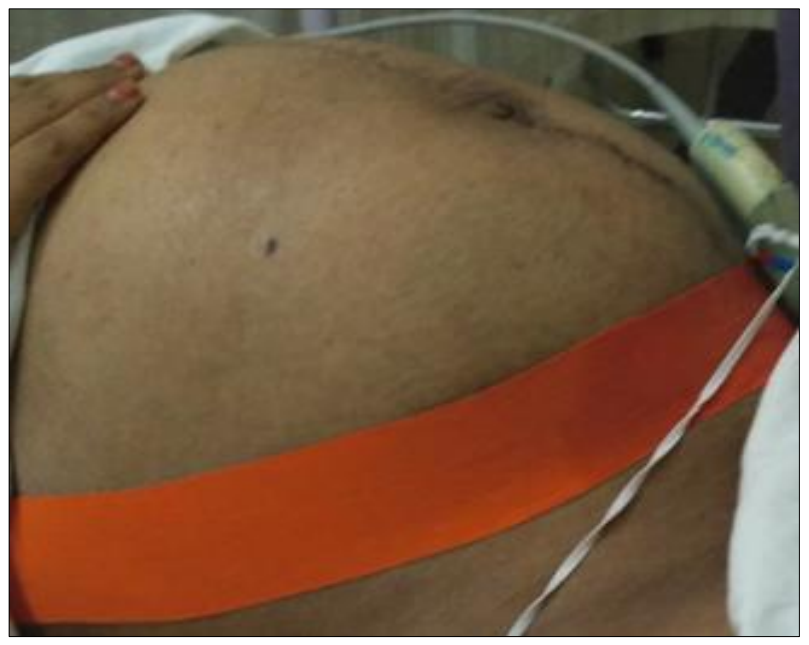

Figure 2: KT 'I' technique.

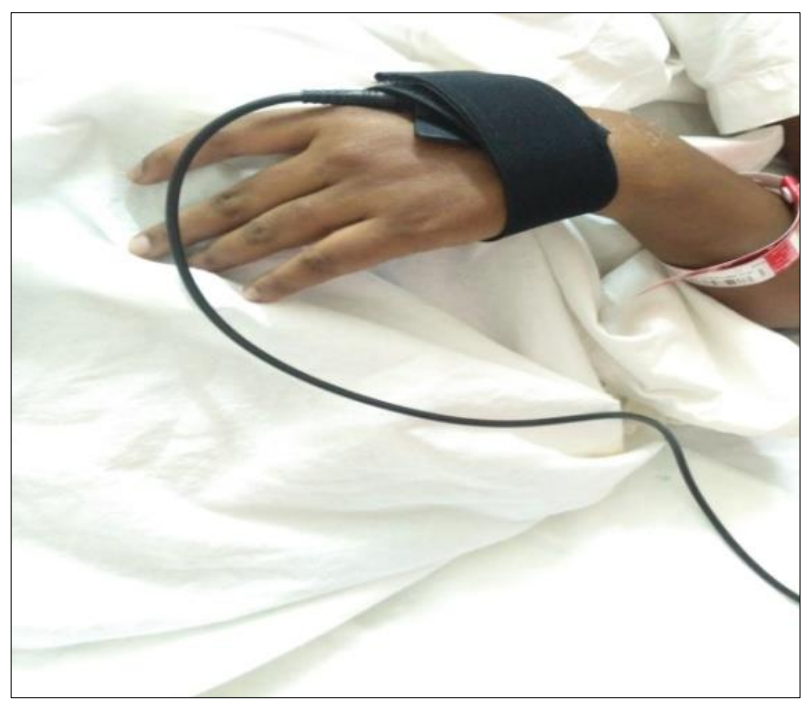

Figure 3: Acu-TENS over Li4 Acupoint.

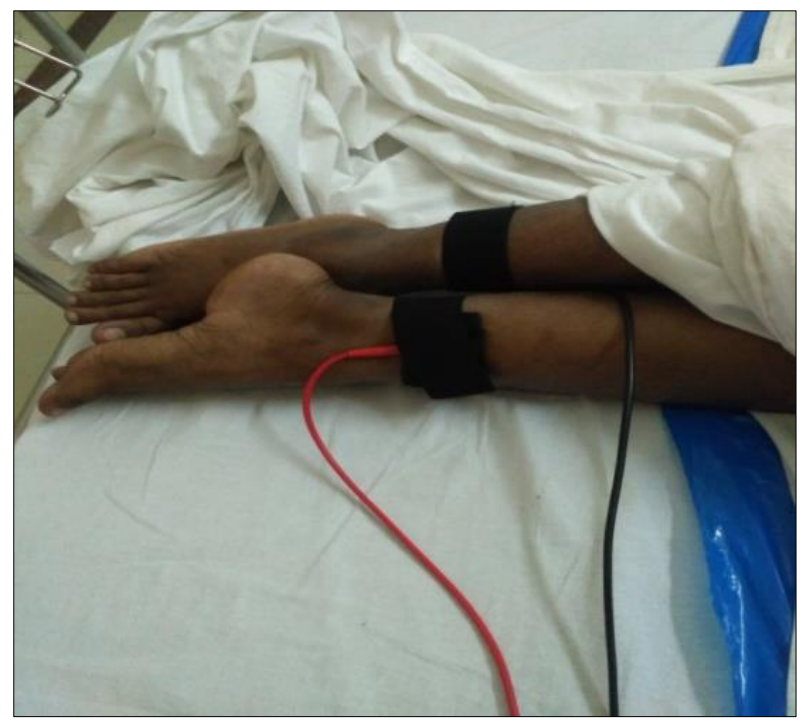

Figure 4: Acu-TENS over Sp6 Acupoints.

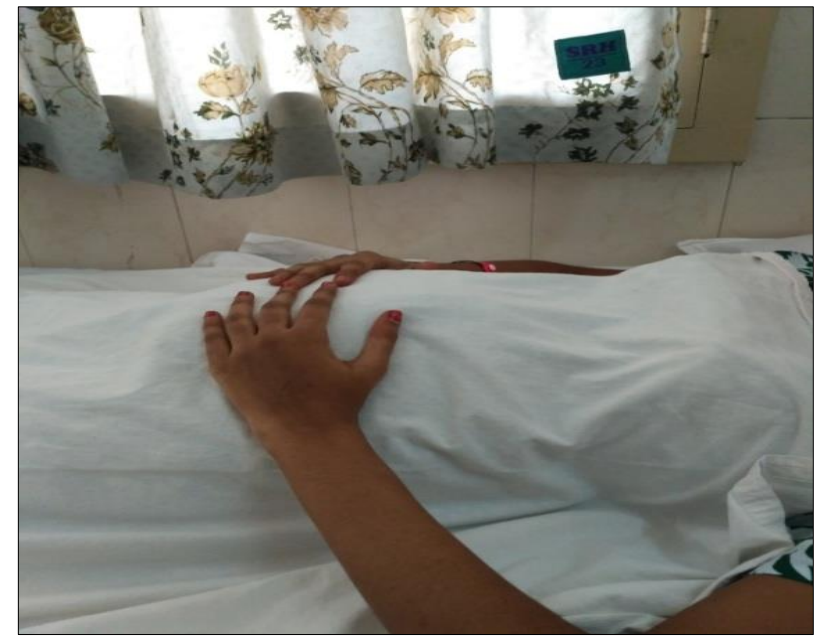

Figure 5: Diaphragmatic breathing.

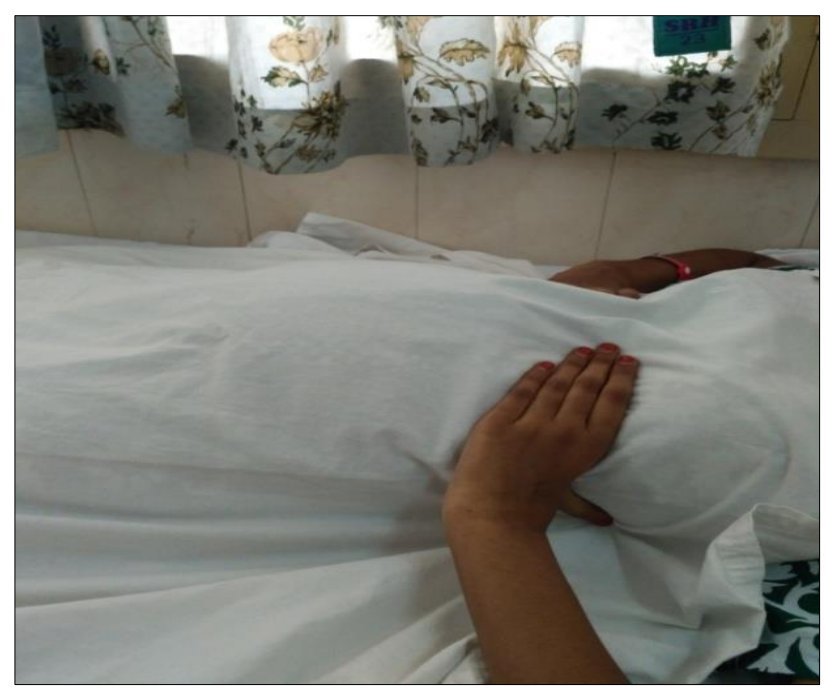

Figure 6: Costal breathing.

In Group B, a portable Acu-TENS unit with 2 pairs of rubber electrode pads measuring $30 \times 30 \mathrm{~mm}$ were placed on subjects' skin over specific acupressure points. The Hegu point (Li4) on both hands located midpoint between $1^{\text {st }}$ and $2^{\text {nd }}$ carpal bones on first web space in the dorsal side of hand (Figure 3) and the Sanyinjiao point (Sp6) on both legs located $5 \mathrm{~cm}$ above medial malleolus (Figure 4) were stimulated. TENS parameters used in this study were $100 \mathrm{~Hz}$ frequency with burst frequency of $2 \mathrm{~Hz}$; $0.25 \mathrm{~ms}$ pulse duration and output intensity was individually titrated between 10 and $18 \mathrm{~mA}$, to elicit a tingling sensation. It was applied throughout first stage of labor. ${ }^{21-23}$

Participants in both groups performed breathing exercises during uterine contractions. Initially, they performed diaphragmatic breathing in a comfortable position by placing their hands over abdomen (Figure 5). They were informed to take a deep breath through nose and notice their abdomen bulge out, then breathe out air slowly through mouth and relax. As uterine contractions became 
stronger and frequent, they were asked to perform costal breathing exercise from any comfortable position, by taking deep breath through nose and breathe out air from mouth slowly and relax (Figure 6).

Visual analogue scale (VAS) was used to assess pain intensity level during first stage of labor. It is a $10 \mathrm{~cm}$ horizontal line with one end described as no pain (score 0 ) and the other end described as worst pain (score 10). ${ }^{24}$ VAS values for group A were measured before and after $\mathrm{KT}$ application of ' $\mathrm{H}$ ' technique at $3-5 \mathrm{~cm}$ cervical dilatation and ' $\mathrm{I}$ ' technique at $7-8 \mathrm{~cm}$ cervical dilatation. VAS values for Group B were measured before application of Acu-TENS and after 30 and 60-minutes post Acu-TENS application.

A stopwatch was used to measure duration of active phase of labor first stage, which is the time between cervical dilatation $>3 \mathrm{~cm}$ to complete dilatation. Apgar score was used to assess neonatal well-being which was measured at 1 minute and 5 minutes after baby birth. ${ }^{25}$ Mode of delivery was noted from the hospital birth records.

\section{RESULTS}

Data collected were statistically analyzed and reported as mean \pm SD. Paired and unpaired ' $t$ ' tests were used to find out statistical differences. A 2-tailed test of significance of $<0.05$ was considered statistically significant. SPSS version 20 for Windows and Microsoft Excel were used for data analysis. The study methodology flowchart is depicted in Figure 7.

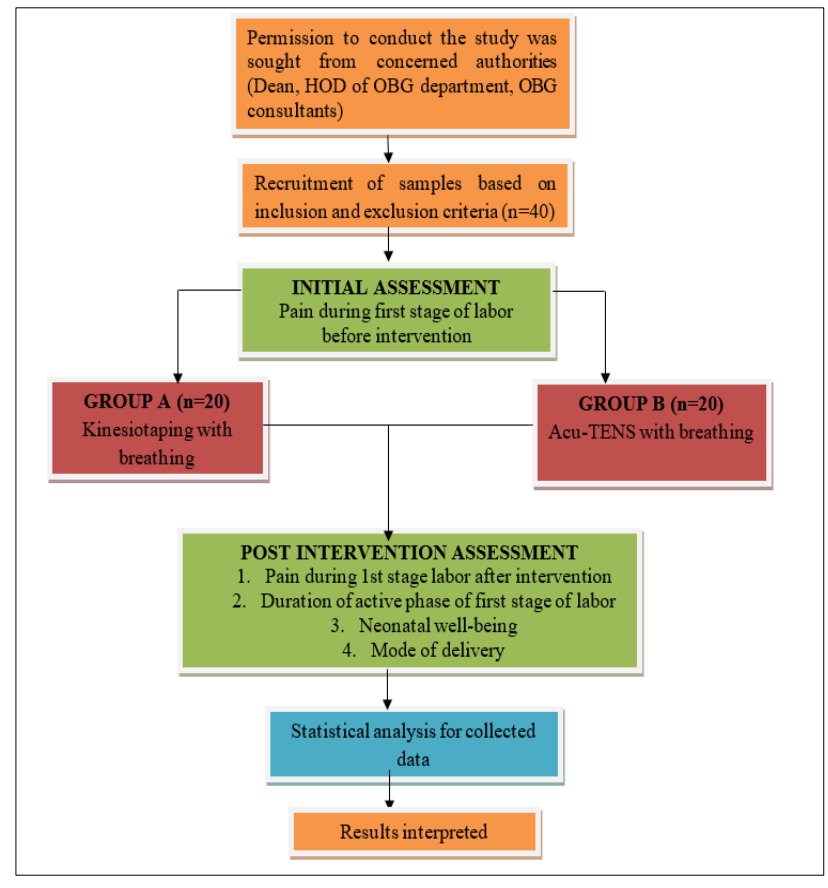

Figure 7: Study methodology flowchart.

\section{Demographic characteristics of the participants in Group A and $B$}

They were analyzed using unpaired ' $t$ ' test and no significant differences in age (years), weight $(\mathrm{kg})$, height $(\mathrm{cm})$, BMI $\left(\mathrm{kg} / \mathrm{m}^{2}\right)$ and gestational age (weeks) were found between the two groups, showing that the samples were homogenous (Table 1).

Table 1: Participants' demographic characteristics.

\begin{tabular}{|c|c|c|c|c|c|}
\hline Characteristics & $\begin{array}{l}\text { Group A } \\
\text { Mean } \pm \text { SD }\end{array}$ & $\begin{array}{l}\text { Group B } \\
\text { Mean } \pm \text { SD }\end{array}$ & t-value & p-value & Significance \\
\hline Age (years) & $25.4 \pm 2.257$ & $25.45 \pm 2.481$ & -0.067 & 0.947 & NS \\
\hline Body weight $(\mathrm{kg})$ & $72.44 \pm 10.65$ & $71.51 \pm 8.869$ & 0.300 & 0.766 & NS \\
\hline Height $(\mathrm{cm})$ & $159.3 \pm 5.486$ & $159.9 \pm 4.483$ & -0.410 & 0.684 & NS \\
\hline BMI $\left(\mathrm{kg} / \mathrm{m}^{2}\right)$ & $28.67 \pm 4.688$ & $28.06 \pm 4.008$ & 0.442 & 0.661 & NS \\
\hline Gestational age (weeks) & $38.6 \pm 1.06$ & $38.42 \pm 1.094$ & 0.529 & 0.600 & NS \\
\hline
\end{tabular}

Table 2: VAS scores before and after KT in Group A.

\begin{tabular}{|lllclll|}
\hline Sr. No. & VAS & Mean & Mean difference & SD & t-value & Sig $(2$-tailed $)(\mathbf{p}<0.05)$ \\
\hline 1 & Pre test & 8.000 & 2.2 & 1.486 & \multirow{2}{*}{8.543} & 0.000 \\
\hline 2 & Post test & 5.800 & & 1.989 & \\
\hline
\end{tabular}

Table 3: VAS scores before and after Acu-TENS in Group B.

\begin{tabular}{|lllclll|}
\hline Sr. No. & VAS & Mean & Mean difference & SD & t-value & Sig $(2$-tailed $)(\mathbf{p}<0.05)$ \\
\hline 1 & Pre test & 8.600 & 1.25 & 0.9947 & \multirow{2}{*}{12.583} & 0.000 \\
\hline 2 & Post test & 7.350 & & 1.039 & Pain values \\
\hline
\end{tabular}




\section{Comparison of VAS scores before and after KT in Group A}

Pre-test and post-test VAS values in Group A were analyzed using paired ' $t$ ' test (Table 2 ). The mean pain score pre-intervention is 8.000 and post-intervention is 5.800 , was statistically significant $(\mathrm{p}=0.000)$ indicating significant change in VAS scores in subjects who received $\mathrm{KT}$ with breathing exercises.

\section{Comparison of VAS scores before and after Acu-TENS in Group B}

Pre-test and post-test scores of VAS in group B were analyzed using paired ' $t$ ' test (Table 3 ). The mean pain score pre-intervention is 8.600 and post-intervention is 7.350, was statistically significant $(\mathrm{p}=0.000)$ indicating significant change in VAS scores in subjects who received Acu-TENS with breathing exercises.

Table 4: Post-test values of VAS between group A and B.

\begin{tabular}{|c|c|c|c|c|c|c|}
\hline \multirow{2}{*}{ Sr. No. } & \multirow{2}{*}{$\begin{array}{l}\text { Post-test values of } \\
\text { VAS }\end{array}$} & \multicolumn{3}{|c|}{ Pain values } & \multirow{2}{*}{ t-value } & \multirow{2}{*}{$\begin{array}{l}\text { Sig (2-tailed) } \\
(\mathbf{p}<0.05)\end{array}$} \\
\hline & & Mean & Mean difference & SD & & \\
\hline 1 & Group A & 5.800 & \multirow{2}{*}{-1.55} & 1.989 & \multirow{2}{*}{-3.088} & \multirow{2}{*}{0.004} \\
\hline 2 & Group B & 7.350 & & 1.039 & & \\
\hline
\end{tabular}

Table 5: Active phase duration in first stage labor.

\begin{tabular}{|c|c|c|c|c|c|c|}
\hline \multirow{2}{*}{ Sr. No. } & \multirow{2}{*}{ Groups } & \multicolumn{3}{|c|}{ Labor duration } & \multirow{2}{*}{ t-value } & \multirow{2}{*}{$\begin{array}{l}\text { Sig (2-tailed) } \\
(p<0.05)\end{array}$} \\
\hline & & Mean & Mean difference & SD & & \\
\hline 1 & Group A & 317.25 & \multirow{2}{*}{60.25} & 269.26 & & \\
\hline 2 & Group B & 257.00 & & 165.43 & 1.010 & 0.319 \\
\hline
\end{tabular}

Table 6: Mode of delivery.

\begin{tabular}{|lll|}
\hline Mode of delivery & Group A & Group B \\
\hline Spontaneous vaginal delivery & $6(30 \%)$ & $6(30 \%)$ \\
\hline Vacuum delivery & $7(35 \%)$ & $9(45 \%)$ \\
\hline Caesarean section & $7(35 \%)$ & $5(25 \%)$ \\
\hline
\end{tabular}

Table 7: Apgar score values.

\begin{tabular}{|c|c|c|c|c|c|}
\hline \multirow{2}{*}{ Groups } & \multicolumn{3}{|c|}{ Apgar score } & \multirow{2}{*}{ t-value } & \multirow{2}{*}{$\begin{array}{l}\text { Sig (2-tailed) } \\
(p<0.05)\end{array}$} \\
\hline & Mean & Mean difference & SD & & \\
\hline \multicolumn{6}{|c|}{ Apgar score at 1 minute } \\
\hline Group A & 7.60 & \multirow{2}{*}{-0.1} & 0.753 & \multirow{2}{*}{-0.406} & \multirow{2}{*}{0.687} \\
\hline Group B & 7.70 & & 0.801 & & \\
\hline \multicolumn{6}{|c|}{ Apgar score at 5 minutes } \\
\hline Group A & 8.700 & \multirow{2}{*}{-0.05} & 0.470 & \multirow{2}{*}{-0.282} & \multirow{2}{*}{0.780} \\
\hline Group B & 8.750 & & 0.638 & & \\
\hline
\end{tabular}

\section{Comparison of VAS scores between 2 groups}

Post-test values of VAS scores of Group A and B were analyzed by unpaired ' $\mathrm{t}$ ' test (Table 4). The post-test mean VAS of Group A (5.800) is lesser than post-test mean VAS of Group B (7.350), showed a statistical significant change in pain intensity levels $(\mathrm{p}=0.004)$ between groups, favouring Group A which had greater significant reduction in mean VAS scores.

\section{Active phase of $1^{\text {st }}$ stage labor duration in Group A and B}

Post-test values of active phase duration in first stage labor for Group A and B were analyzed using unpaired ' $t$ ' test (Table 5). The mean duration in Group A (317.25 minutes) is greater than the mean duration in group B (257 minutes). The $\mathrm{p}$ value obtained is 0.319 which is $>0.05$. There is no significant change in active phase duration between the 2 groups.

\section{Mode of delivery in Group A and B}

In both groups, 6 cases had spontaneous vaginal delivery. CS was increased in Group A [35\% (7/20)] than in Group B $[25 \%(5 / 20)]$ (Table 6). The reasons for emergency CS's in both groups were non-progression of labor, fetal distress, dilatation arrest with non-assuring FHR and prolonged $2^{\text {nd }}$ stage of labor. Use of vacuum delivery was increased in Group B [45\% (9/20)] than in Group A [35\% 
(7/20)]. It was performed due to maternal exhaustion, poor maternal effort and prolonged $2^{\text {nd }}$ stage of labor.

\section{Apgar scores in Group A and B}

The mean Apgar scores at 1 minute and 5 minutes of each group were non-significant. At 1 minute postdelivery, in Group A, 15 babies had score 8, 2 had score 7, 3 had score of 6 whereas, in Group B, 17 babies had score 8, 3 had scores 5, 6 and 7 respectively. At 5 minutes post-delivery, in Group A, 14 babies had score 9, 6 had score 8 whereas, in Group B, 17 babies had score 9, 1 had score 8 and 2 had score 7 (Table 7 ).

\section{DISCUSSION}

Pain relief in labor is a major goal in maternity care. Individual pain perception depends not only on the intensity and duration of uterine contractions and speed of cervical dilatation, but also on complex emotional factors like expectations and cultural facts. ${ }^{18}$ Women with high pain scores and distress-related thoughts during labor have resulted in longer labors and more likely needed instrumental delivery. Maternal distress during first stage of labor was related to higher incidences of abnormal FHR patterns and required neonatal assistance. ${ }^{14}$ Women with fear of pain during uterine contractions can lead to pain fear cascade, that increases catecholamine release, particularly, adrenaline that promotes vasoconstriction and stops oxytocin production, decreases effective uterine contractions and placental blood flow leading to exhaustion, cervical dystocia, fetal suffering and postpartum post-traumatic stress disorder. ${ }^{13}$

Most of the women, especially primigravidas, require some pharmacologic therapy for labor pain relief. The commonly administered form of pain control during labor are epidural analgesia and narcotics, but they are not without complications. ${ }^{19}$ This study proves that non pharmacological methods such as KT, Acu-TENS and breathing exercises can promote better pain management without any maternal and neonatal adverse effects and encourage active participation of women in the decision making process, with the aim of positive child birth experiences. ${ }^{16,17,19,26-28}$

\section{Kinesiotaping on labor pain and first stage labor duration}

This study showed that KT significantly reduced labor pain without any adverse maternal and neonatal outcomes. Maria Amelia Miquelutti et al reported that KT provided significant pain and length of active phase reduction during labor with no adverse effects. ${ }^{14}$ Consistent with our study, El-Refaye GE et al also reported its high significance in reducing labor pain and shortening duration of first stage labor. ${ }^{15}$ The effectiveness is by constantly stimulating skin receptors, so that they act on superficial and deep tissues and promote pain relief through gate control theory of pain, as suggested by Melzack and Wall. It also relieves pain by microscopically lifting skin where the taped portion forms convolutions in the skin, increasing the interstitial space, thereby supporting lymph circulation, reducing pressure and irritation on sensory and neural receptors. ${ }^{20}$

In our study, the active phase duration in first stage labor was increased in Group A when compared to the other group. This might be due to delayed labor progression. There is only limited documentation on the effectiveness of KT on labor pain and childbirth duration. ${ }^{15} \mathrm{KT}$ appears to be a safe and acceptable intervention to manage labor pain.

\section{Acu-TENS on labor pain and first stage labor duration}

TENS on acupuncture points works by a combination of central and peripheral actions to release endogenous opioid peptides. Hegu (Li4) points on both hands and Sanyinjiao (Sp6) points on both legs were chosen as these were the traditional acupuncture points used in labor pain relief. Analgesia is achieved by either blocking pain impulses to the brain by increasing A- $\beta$ fibre transmission or by stimulating local release of endorphins. Melzack and Wall (1965) proved that pain was controlled by closing of spinal cord "gate" through activities of nerve cells in cord with modulation by higher centers. Differential release of opiates in central nervous system by TENS has been noted, with a frequency of $2 \mathrm{~Hz}$ triggering the release of enkephalins and $\beta$-endorphins and $100 \mathrm{~Hz}$ stimulation selectively increasing release of dynorphin in spinal cord. A combination of both frequencies allows synergistic interaction among the 3 endogenous opiates and provides powerful analgesic effects. ${ }^{16,17}$

This study showed that Acu-TENS significantly reduced labor pain without any side effects to the mother and neonate. Similarly, An-Shine Chao et al applied TENS on acupuncture points during first stage of labor and reported VAS score reduction $>3 .{ }^{16}$ Kaplan et al proved TENS significantly reduced amount of analgesic drug administered to individual patients and no adverse effects on mothers or newborns were noted. ${ }^{17}$ Peng $\mathrm{T}$ et al also reported that VAS scores decreased by $>25 \%$ for $68.6 \%$ in the TENS treatment group. ${ }^{21}$ Bedwell et al concluded that patients who were administered TENS to acupuncture points were less likely to report severe pain and majority of women using TENS would use it again in a future labor. ${ }^{22}$ Lee $\mathrm{MK}$ et al reported that acupressure on Sp6 significantly reduced labor pain scores and duration of labor. ${ }^{23}$ Van der Spank et al considered TENS as a safe complement of coping skills, such as breathing and relaxation techniques. ${ }^{26}$

The duration of active phase in first stage labor was reduced in Group B which received Acu-TENS. Likewise, Kaplan et al proved TENS significantly reduced duration of the first stage of labor for nulliparas and multiparas. ${ }^{17}$ Thakur and Patidar reported that mean duration of first stage labor was 
less in TENS group and tramadol group than in control group..$^{29}$ Bundsen $\mathrm{P}$ et al, found there was a slight tendency in the TENS group toward increased uterine activity. ${ }^{30}$ This is in agreement with Kubista et al who concluded that apart from the good analgesic effect obtained, an advantage of TENS was the quick course of labor. ${ }^{31}$ Harrison et al, also concluded that primigravids who used TENS in labor had shorter births. ${ }^{32}$ Chao AS et al, in contrast reported that there was no significant difference in first stage labor duration and TENS application did not alter length of the first stage. ${ }^{16}$

\section{Breathing exercises on labor pain and first stage labor duration}

Breathing exercises are thought to be a key for relaxation as they can assist women to cope with pain of uterine contractions. In this study, breathing exercises were done as an adjunct in combination with Acu-TENS and KT for coping with labor pain by lessening anxiety level of primigravidas. Yildirim and Sahin concluded that breathing exercises were effective in decreasing pain perception by pregnant women, resulting in better satisfactory birth experiences. ${ }^{19}$ The results of Kamali Fard et al showed that breathing techniques significantly reduced cesarean rate. ${ }^{33}$ Tafazoli et al also showed that breathing exercises significantly shortened first stage of labor and decreased the need for induction, but had no significant effects on Apgar scores and rate of cesarean section. ${ }^{34}$

\section{KT and Acu-TENS on Apgar score}

The Apgar assessment has proven to be a good predictor of neonatal mortality and morbidity. ${ }^{35}$ It describes the newborn's condition immediately after birth and is a tool for standardized assessment. ${ }^{36}$ Mello et al discussed that few studies reported no significant differences in Apgar scores at the first and fifth minute. ${ }^{37}$ Identically, in this study, both groups demonstrated statistically nonsignificant Apgar scores. This proves that KT and AcuTENS has no unfavorable effects on the newborn and can be safely administered in labor.

\section{KT and Acu-TENS on mode of delivery}

This study showed increased caesarean delivery in group A $(\mathrm{KT})$, whereas more use of instrumental delivery in group B (TENS). Not much literature is available analyzing KT application and mode of delivery. Contrary to our study, An-Shine Chao et al reported increased use of operative delivery in the TENS group. ${ }^{16}$ Bundsen et al, also found greater use of vacuum extraction in control than in the TENS group. ${ }^{30}$ Harrison et al, and van der Ploeg et al in their studies found no significant difference in the occurrence of normal and cesarean sections with TENS usage. ${ }^{32,38}$

Pain perception for primigravidas was greatly lessened after KT application in the first stage of labor when compared with Acu-TENS. KT application did not significantly reduce active phase duration in first stage labor. TENS applied over acupuncture points could very well be used as an adjunct for controlling labor pain and also for reducing first stage labor duration. As a non-pharmacological resource, significant positive effects on pain with no negative effects on maternal and neonatal outcomes justifies KT and Acu-TENS application in labor.

Some of the limitations of this study include small sample size, no control group and inclusion of primigravidas only. The main limitation was the difference between each participant's ability to tolerate labor pain and the psychological status of pregnant women during the treatment period. Future studies can be done with larger sample size, can include multiparous women and other non-pharmacological interventions also can be compared. TENS application on other Acu-points can also be considered.

\section{CONCLUSION}

This study proves that KT produced significantly better pain relief than Acu-TENS in first stage of labor among primigravidas. No significant differences were noted between two groups for the active phase duration in first stage labor and Apgar scores at 1 minute and 5 minutes post-delivery. CS rate was slightly increased in Group A compared to Group B. No obvious adverse effects in maternal and neonatal outcomes were noted between the groups. KT and Acu-TENS combined with breathing exercises could be used safely as an adjunct for pain control in the first stage of labor.

\section{ACKNOWLEDGMENTS}

Authors would like to thank all the patients who took part in this study.

Funding: No funding sources

Conflict of interest: None declared

Ethical approval: Not required

\section{REFERENCES}

1. Sapsford R, Bullock-Saxton J, Markwell S. Women's health: A text-book for physiotherapists. $1^{\text {st }}$ ed. London: WB Saunders Company Ltd; 1998:192-203.

2. Betrán AP, Ye J, Moller AB, Zhang J, Gülmezoglu AM, Torloni MR. The increasing trend in caesarean section rates: global, regional and national estimates: 1990-2014. PloS One. 2016;11(2):e0148343.

3. NFHS - 4, 2015-16. India fact sheet. Available at: http://www.rchiips.org/nfhs. Accessed on $15^{\text {th }}$ March 2019.

4. NFHS - 4, 2015-16. State fact sheet - Tamil Nadu. Available at: http://www.rchiips.org/nfhs. Accessed on $15^{\text {th }}$ March 2019.

5. Vijayalaxmi KG, Urooj A. Influence of maternal factors on mode of delivery and birth weight in urban pregnant women. J Hum Ecol. 2009;25(2):133-6.

6. WHO statement on CS rates. 2015. Available at: http://www.who.int/reproductivehealth/. Accessed on $9^{\text {th }}$ January 2019. 
7. Abushama M, Ahmed B. CS on request. Saudi Med J. 2004;25(12):1820-3.

8. Pang MW, Leug TN, Leug TY, Lai CY, Lau TK, Chung KH. Determinants of preference for elective CS in Hong Kong Chinese pregnant women. Hong Kong Med J. 2007;13(2):100-5.

9. Adams ED, Bianchi AL. A practical approach to labor support. JOGNN. 2008;37:106-15.

10. Mukherjee SN. Rising cesarean section rate. The J Obstet Gynecol India. 2006;56(4):298-300.

11. Mantle J, Haslam J, Barton S, Cardozo L. Physiotherapy in obstetrics and gynaecology. $2^{\text {nd }} \mathrm{Ed}$. Edinburgh: Elsevier limited; 2004.

12. Brown ST, Douglas C, Flood LP. Women's evaluation of intra partum non pharmacological pain relief methods used during labor. J Perinat Educ. 2001;10:1-8.

13. Trout KK. The neuromatrix theory of pain: Implications for selected non-pharmacologic methods of pain relief for labor. J Midwifery Womens Health. 2004;49(6):482-8.

14. Miquelutti MA, Cecatti JG. KT for pain control during labor: Protocol of a RCT. Nurs Health Sci. 2017;19(1):95-9.

15. El-Refaye G, El Nahas E, Ghareeb H. Effect of KT therapy combined with breathing exercises on childbirth duration and labor pain: a RCT. Bullet Faculty Phy Ther. 2016;21(1):23-31.

16. Chao AS, Chao A, Wang TH, Chang YC, Peng HH, Chang SD. Pain relief by applying TENS on acupuncture points during the first stage of labor: a randomized double-blind placebo-controlled trial. Pain. 2007;127(3):214-20.

17. Kaplan B, Rabinerson D, Lurie S, Bar J, Krieser UR, Neri A. TENS for adjuvant pain-relief during labor and delivery. Int J Gynaecol Obstet 1998;60(3):251-5.

18. Kamali Fard M, Shahnazi M, Allahverdizadeh S, Toraby S, Ghahvechi A. The efficacy of massage therapy and breathing techniques on pain intensity and physiological responses to labor pain. J Caring Sci. 2012:173-78.

19. Yildirim G, Sahin NH. The effect of breathing and skin stimulation techniques on labor pain perception of Turkish women. Pain Res Manag. 2004;9(4):183-7.

20. Kaplan S, Alpayci M, Karaman E. Short-term effects of KT in women with pregnancy related low back pain: a randomized controlled clinical trial. Med Sci Monit. 2016;22:1297-301.

21. Peng T, Li XT, Zhou SF. TENS on acupoints relieves labor pain: A non-randomized controlled study. Chin J Integ Med. 2010;16(3):234-8.

22. Bedwell C, Dowswell, Neilson JP, Lavender T. The use of TENS for pain relief in labor: A review of the evidence. Midwifery. 2011;27(5):141-8.

23. Lee MK, Chang SB, Kang DH. Effects of Sp6 acupressure on labor pain and length of delivery time in women during labor. J Altern Complement Med. 2004;10(6):959-65.
24. Bijur PE, Silver W, Gallagher EJ. Reliability of VAS for measurement of acute pain. Acad Emerg Med. 2001;8:1153-7.

25. Ratcliffe FM, Evans JM. Neonatal wellbeing after elective caesarean delivery with general, spinal and epidural anaesthesia. $\mathrm{Eu} \mathrm{J}$ Anaesthesiol. 1993;10(3):175-81

26. Van der Spank JT, Cambier DC, De Paepe HM, Danneels LA, Witvrouw EE, Beerens L. Pain relief in labor by TENS. Arch Gynecol Obstet. 2000;264(3):131-6.

27. Vakilian K, Keramat A. The effects of breathing techniques with and without aromatherapy on the length of active phase and second stage of labor. Nursing Midwifery Stud. 2013;1:115-9.

28. Levett KM, Smith CA, Bensoussan A, Dahlen HG. Complementary therapies for labour and birth study: a randomised controlled trial of antenatal integrative medicine for pain management in labour. BMJ open. 2016;6(7):e010691.

29. Ratna T, Rekha P. Comparative study of TENS and tramadol hydrochloride for pain relief in labor. J Obstet Gynecol Ind. 2004;54(4):346-50.

30. Bundsen P, Ericson K, Peterson LE, Thiringer K. Pain relief in labor by TENS. Acta Obstet Gynecol Scand. 1982;61:129-36.

31. Kubista E, Kucera H, Riss P. The effect of TENS on labor pain. Geburtshilfe Frauenheilkd. 1978;38:107984.

32. Harrison RF, Woods T, Shore M, Mathews G, Unwin A. Pain relief in labor using TENS. A TENS/TENS placebo-controlled study in two parity groups. $\mathrm{Br} \mathrm{J}$ Obstet Gynaecol. 1986;93(7):739-46.

33. Kamali Fard M, Shahnazi M, Torabi S, Gahvechy Jaeepeyma A, Azari S. The efficacy of breathing techniques in physiological response to labor pain and pain intensity. $\mathrm{J}$ Caring Sci Nurs Midwif. 2009;3(12):33-8.

34. Tafazoli M, Yosef Zadeh S, Behnam Veshani H, Keivanlo F, Keivanlo M, Delbari F. The effect of training respiratory techniques on labor. Beihagh. 2000;6(1):24-31.

35. Smith, Elizabeth W. The relationship between one- and five-minute APGAR scores and linguistic functioning as measured by the test of language development. Retro Theses Dissertat. 1982:657.

36. Papile LA. The Apgar score in the 21st century. N Engl J Med. 2001;344:519-20.

37. Mello LFD, Nóbrega LF, Lemos A. TENS for pain relief during labor: A systematic review and metaanalysis. Revista Brasileira de Fisioterapia. 2011;15(3):175-84.

38. Van der Ploeg JM, Vervest HA, Liem AL, Schagen van Leeuwen JH. TENS during the first stage of labor: A RCT. Pain. 1996;68(1):75-8.

Cite this article as: Rajappan R, Balamurugan $S$, Selvaganapathy K. Effectiveness of kinesiotaping and Acu-TENS on maternal and neonatal outcomes in the first stage of labor among primigravidas. Int $\mathrm{J}$ Reprod Contracept Obstet Gynecol 2020;9:247-54. 